\title{
Discovery and molecular characterization of a novel enamovirus, Grapevine enamovirus-1
}

\author{
João Marcos Fagundes Silva ${ }^{1} \cdot$ Maher Al Rwahnih $^{2} \cdot$ Rosana Blawid $^{1} \cdot$ \\ Tatsuya Nagata ${ }^{1}$. Thor Vinícius Martins Fajardo ${ }^{3}$
}

Received: 13 April 2017/ Accepted: 29 May 2017

(C) Springer Science+Business Media New York 2017

\begin{abstract}
In this study, we describe a novel putative Enamovirus member, Grapevine enamovirus-1 (GEV-1), discovered by high-throughput sequencing (HTS). A limited survey using HTS of 17 grapevines (Vitis spp.) from the south, southeast, and northeast regions of Brazil led to the detection of GEV-1 exclusively on southern plants, infecting four grapevine cultivars (Cabernet Sauvignon, Semillon, CG 90450, and Cabernet franc) with a remarkable identity of around $99 \%$ at the nucleotide level. This novel virus was only detected in multiple-virus infected plants exhibiting viral-like symptoms. GEV-1 was also detected on a cv. Malvasia Longa by RT-PCR. We performed graft-transmissibility assays on GEV-1. The organization, products, and cis-acting regulatory elements of GEV-1 genome are also discussed here. The near complete genome sequence of GEV-1 was obtained during the course of this study, lacking only part of the $3^{\prime}$ untranslated terminal region. This is the first report of a virus in the family Luteoviridae infecting grapevines. Based on its genomic properties and phylogenetic analyses, GEV-1 should be classified as a new member of the genus Enamovirus.
\end{abstract}

Edited by Thomas Hohn.

Thor Vinícius Martins Fajardo

thor.fajardo@embrapa.br

1 University of Brasília, Brasília, DF, Brazil

2 Department of Plant Pathology, University of California, Davis, CA, USA

3 Embrapa Grape \& Wine, Bento Gonçalves, RS, Brazil
Keywords High-throughput sequencing · Virus discovery · Luteoviridae · Grapevine enamovirus-1 . GEV-1

\section{Text}

A limited survey was performed on 17 grapevine samples subjected to high-throughput sequencing (HTS). These plants were collected from three different grapevine collections from the south (11), northeast (2), and southeast (4) regions of Brazil, and the symptoms in the $V$. vinifera hosts were downward rolling of leaves and reddening or yellowing, whereas other genotypes were asymptomatic $[1,2]$. Following a typical metagenomic pipeline using HTS, we were able to identify a new putative Enamovirus member, tentatively named Grapevine enamovirus-1 (GEV-1), infecting distinct grapevine cultivars in Brazil. The family Luteoviridae comprises three genera, Luteovirus, Polerovirus, and Enamovirus. These viruses have a positive-sense RNA genome of around 5.2-6.3 kb [3]. The genus Enamovirus has only one recognized viral species, Pea enation mosaic virus-1 (PEMV-1), and two putative members, Citrus vein enation virus (CVEV) and Alfalfa enamovirus-1 (AEV-1). The systemic movement of PEMV-1, type species of the genus Enamovirus, is provided by an umbravirus [4], although this has not been reported for the remaining putative enamoviruses. Viruses in the family Luteoviridae are transmitted by aphids in a circulative non-persistent manner [3].

To characterize the viromes of these plants, doublestranded RNA (dsRNA) extracts were subjected to HTS on the Illumina HiSeq 2000 platform. Briefly, reads were trimmed, de novo assembled (CLC bio, Qiagen, USA), and subjected to a BLASTX search against the NCBI viral 
RefSeq database. This led to the identification of a novel luteovirid in four grapevine samples of different cultivars: Cabernet Sauvignon (S1M-CS), CG 90450 (S12-CG), Semillon (S16-SE), and Cabernet franc (S19-CF). All vines exhibiting symptoms of viral infection were collected from the Rio Grande do Sul (RS) state, south region of Brazil. Seven sets of primers (Table 1) were designed to confirm the infection of GEV-1 on the S1M-CS vine, and amplicons corresponding to sets 1,6 , and I were sequenced, which verified an identity of $99 \%$ with the contigs built by de novo assembly. Contigs with Luteoviridae hits in the samples S1M-CS (1), S12-CG (5), S16-SE (1), and S19-CF (5) covered, respectively, 99, 93, 99, and 95\% of the near complete GEV-1 sequence, obtained after rapid amplification of the cDNA ends (RACE) in the $5^{\prime}$ extremity by the Terminal deoxynucleotidyl transferase (TdT) method. After scaffolding of the fragmented S12-CG and S19-CF contigs, an identity of around $99 \%$ at the nucleotide level was verified for GEV-1 among these four samples. Mixed infections were present in all GEV-1 positive samples $[1,2]$ and the virus communities in these samples included 11 pathogens: Grapevine Cabernet Sauvignon reovirus (GCSV), Grapevine vein clearing virus (GVCV), Grapevine Red Globe virus (GRGV), Grapevine leafroll-associated virus 2 and 3 (GLRaV-2, -3), Grapevine rupestris stem pitting-associated virus (GRSPaV), Grapevine virus A (GVA), Grapevine virus B (GVB), Grapevine fleck virus (GFkV), Grapevine rupestris vein feathering virus (GRVFV), and Grapevine yellow speckle viroid 1 (GYSVd-1). Additionally, GEV-1 was detected on a Malvasia Longa vine by RT-PCR during the virus indexing of this cultivar. The near complete genome of GEV-1 isolate CS-BR (6227 bp), lacking only part of the $3^{\prime}$ untranslated sequence, was deposited in GenBank under accession KX645875. The isolate SE-BR near complete sequence
(6176 bp), obtained only by de novo assembly, was also deposited in GenBank under accession KY820716.

To assess the graft transmissibility of the novel virus, cv. Cabernet Sauvignon (S1M-CS) was grafted onto 16 healthy cv. $1103 \mathrm{P}$ plants (V. berlandieri x $V$. rupestris). Grafttransmissibility of GEV-1 was confirmed in 13 out of 16 positive samples by performing RT-PCR 5 months after grafting.

Luteovirids are known to harbor five to ten open reading frames (ORFs) usually displayed as two gene blocks separated by a non-coding intergenic region [5-7]. The $5^{\prime}-$ proximal block contains the two partially overlapping ORFs 1 and 2, plus an additional ORF encoding a silencing suppressor protein (ORF 0) in the genera Enamovirus and Polerovirus. The 3 -proximal gene block contains the ORFs corresponding to the coat protein (ORF 3), an extension of the coat protein translated by an in-frame stop codon readthrough (ORF 5) and a movement protein (ORF 4) located within ORF 3 in the genera Luteovirus and Polerovirus that is absent in the genus Enamovirus. ORFs 3, 4, and 5 are translated from a subgenomic RNA (sgRNA). GEV-1 genomic features (Fig. 1a) are discussed below.

ORF 0 (nt 335-1279) overlaps ORF 1 and potentially encodes a $34.9 \mathrm{kDa}$ protein (P0), presumably a suppressor of host RNAi machinery. The F-box-like domain (LPxxI/ $\mathrm{L}(\mathrm{x} 10-13) \mathrm{P})$ found in the $\mathrm{P} 0$ of polero- and enamoviruses is necessary for its silencing suppressor activity [8, 9]. Interestingly, it was verified that only the first leucine is conserved on GEV-1. ORF 1 (nt 471-2912) potentially encodes an $89.8 \mathrm{kDa}$ protein (P1), it contains a conserved 3C-like serine peptidase followed by the genome-linked viral protein (VPg). The conserved domain $\mathrm{H}(\mathrm{x} 25) \mathrm{D}(\mathrm{x} 70-80) \mathrm{GxSG}$ of the $\mathrm{S} 39$ serine protease is positioned between nt 1350 and 1841 [10]. Alignments
Table 1 Primers used for detection of Grapevine enamovirus-1 (GEV-1)

\begin{tabular}{llll}
\hline Name & Sequence & $5^{\prime}$ nt position & Length (bp) \\
\hline Set1F & CACACTTGCTTCTCTTCTCG & 50 & 749 \\
Set1R & CCAACGTAAGCGAATAGTCG & 798 & \\
Set2F & GTTGGAGAGAGGAAAGAATCGG & 1323 & 684 \\
Set2R & GGGTTTGTCTGTGACCTCATAGTC & 2006 & \\
Set3F & AGGCCAAGAGGGGCAAGAAATTGT & 2434 & 530 \\
Set3R & CGGCAGATTTTGATCTAGCAGCTC & 2963 & \\
Set4F & ACAAGCAGGAGTTGAGGATG & 3423 & 600 \\
Set4R & CGACGAGCATTTTACCCACA & 4022 & \\
Set5F & GGACAGAGGTTGCATTGCGTAT & 4622 & \\
Set5R & TTGAAACCGAGCCAAGTGAGTGTC & 5126 & \\
Set6F & TTCCCTTGGGAGACTCGGTTCTAT & 5263 & \\
Set6R & AAACATGACCACCCGTCTCATAGC & 5997 & 638 \\
SetIF & AAAGTGGTGTGTCGCTATGG & 3850 & \\
SetIR & GGCAAACGAATTTACCAAGAACG & 4487 & \\
\hline
\end{tabular}


a

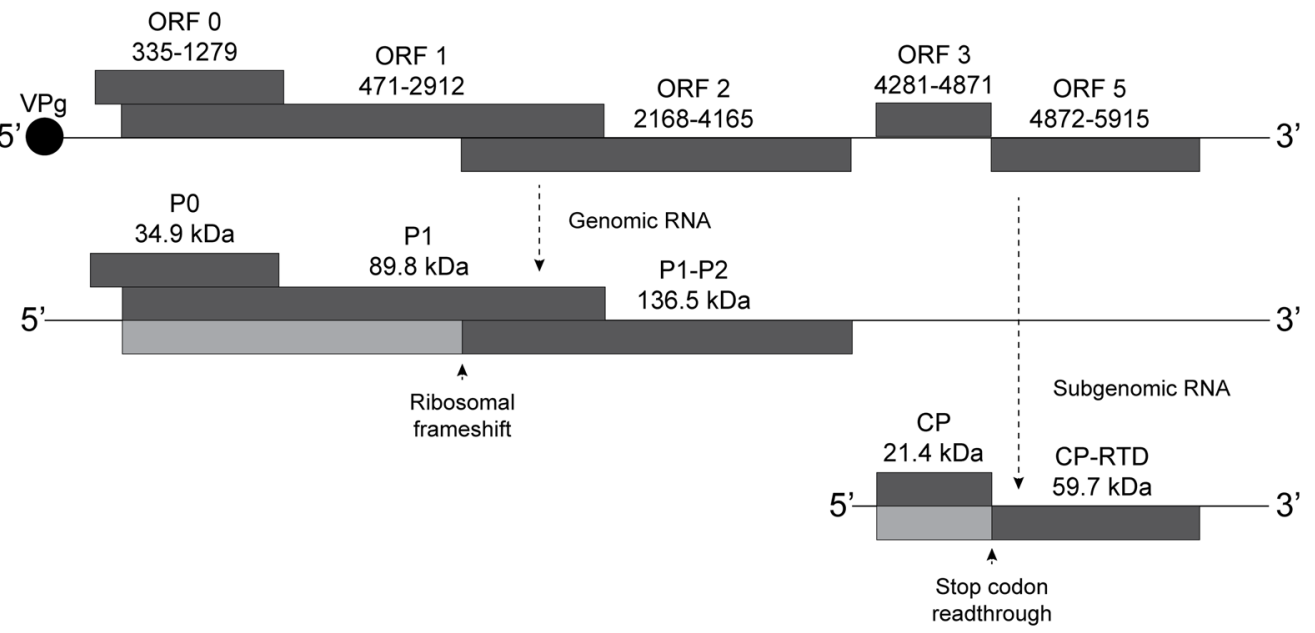

b

P2

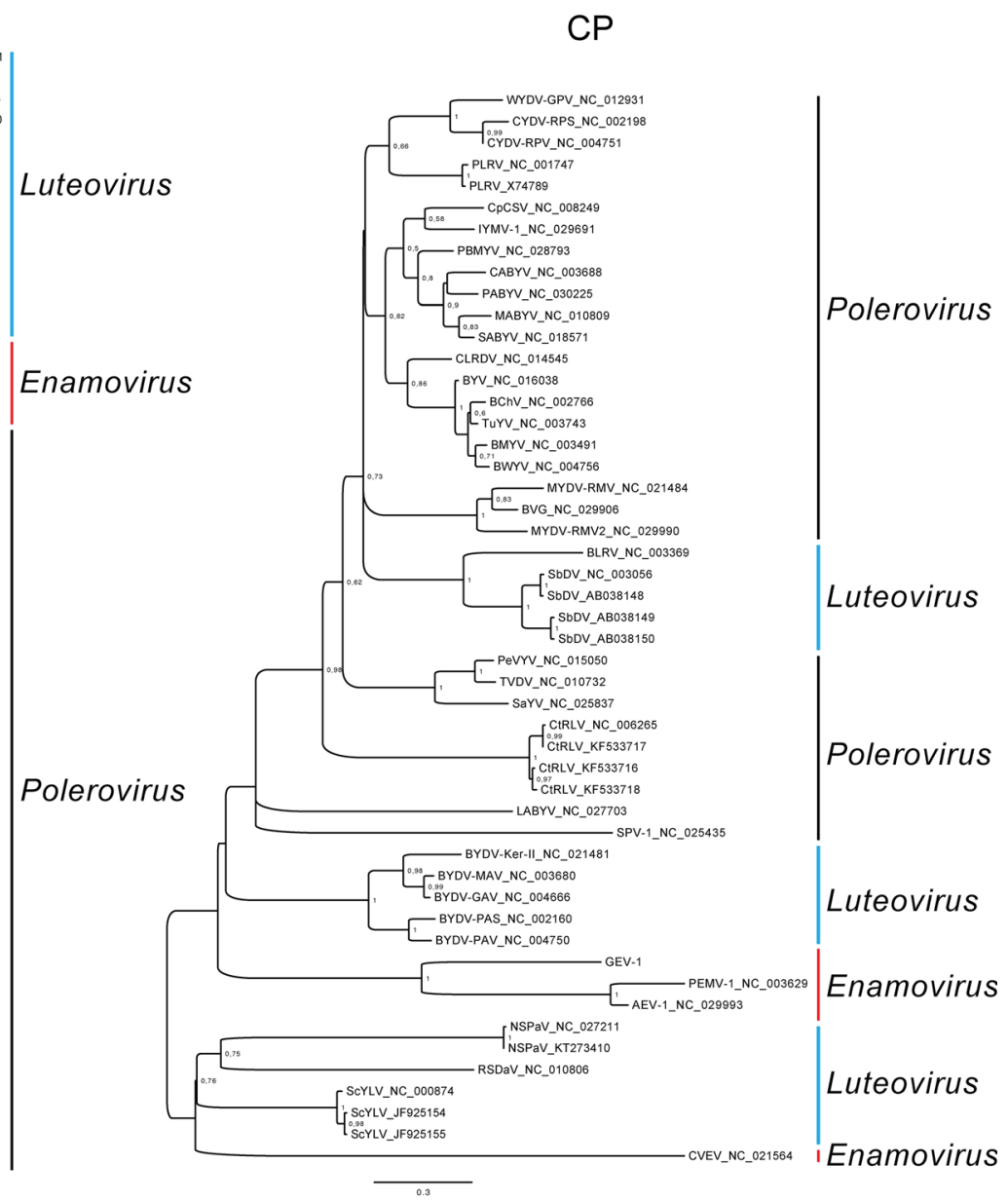

Fig. 1 a GEV-1 genome organization and b Maximum likelihood trees $(\mathrm{JTT}+\mathrm{G}(4)+\mathrm{I}$; Bootstrap $=1000$ replications) for the family Luteoviridae using the $\mathrm{P} 2$ and $\mathrm{CP}$ amino acid sequences. Trees were

inferred with MEGA 7 [28]. Alignments were performed with MUSCLE. Trees were midpoint rooted

with PEMV-1 suggest that the first VPg cleavage site (E/S) at the GEV-1 genome is positioned at nt 1938 [11, 12], but we were unable to deduce the second proteolysis site. The $\mathrm{W}(\mathrm{A}, \mathrm{G}) \mathrm{D}$ motif followed by a DE-rich region [13] is

located between nt 2079 and 2111. ORF 2 (nt 2168-4165) is translated by a -1 frameshift from ORF 1 , originating a fusion protein (P1-P2) containing the RNA-dependent RNA polymerase (RdRp), of a predicted molecular mass of 
$136.55 \mathrm{kDa}$. The highly conserved GDD box motif [14] is located between nt 3869 and 3877. ORF 3 (nt 4281-4871) potentially encodes a $21.4 \mathrm{kDa}$ protein, which corresponds to the coat protein (CP). ORF 5 (nt 4872-5915) encodes the readthrough domain (RTD) of the CP-RTD fusion protein, predicted to have a total molecular mass of $59.7 \mathrm{kDa}$. This protein is needed for efficient aphid transmission [15]. GEV-1 lacks the C-terminal portion of the CP-RTD protein that is responsible for limiting the infection of luteo- and poleroviruses to the phloem [4]. The amino acid identity between GEV-1 and others enamoviruses is below $44 \%$ for all ORFs.

Viruses in the family Luteoviridae employ a wide range of translational mechanisms which are regulated by cisacting RNA elements (CRE) embedded in the virus genome $[6,16]$. GEV-1 ORF 0 possesses a leaky start codon UAUAUGU, allowing the translation of ORF 1 [17, 18]. Two signals are required for the -1 ribosomal frameshift at ORF 1, the heptanucleotide sequence XXXYYYZ and a downstream pseudoknot or very stable RNA secondary structure located six to eight nucleotides from the frameshift site [19]. We found the TTTAAAC sequence located at nt 2168 and a pseudoknot seven nt downstream of this site, predicted with the RNAPKplex program [20]. The CCNNNN tandem repeat motif associated with ORF 3 stop codon readthrough [21] is located between nt 4887 and 4935, 15 nucleotides downstream from the termination site. Remarkably, GEV-1 readthrough site at ORF 3 (UUGUGAUAU) is not similar to any previously reported $\mathrm{Lu}$ teoviridae [18].

Maximum likelihood trees for the family Luteoviridae were estimated based on the P2- and CP-translated sequences (Fig. 1b). The ORF 2 is separated from ORF 3 by an intergenic region which is a probable hot spot for recombination among luteovirids $[22,23]$ so incongruences in the trees when considering these two distinct regions are expected. In both trees, GEV-1 clusters together with PEMV-1 and AEV-1, indicating that GEV-1 is more closely related to the genus Enamovirus.

Using HTS of dsRNA extracts from 17 samples, some of them exhibiting viral-like symptoms, we identified in four samples, within a virus community, a new putative Enamovirus member, provisionally named Grapevine enamovirus-1 (GEV-1), infecting distinct grapevine cultivars from the south region of Brazil. The distinguishing feature of the genus Enamovirus is the lack of a movement protein [3]. No ORF corresponding to this protein could be identified on GEV-1. Bioassays confirmed infection and graft-transmissibility of GEV-1. Due to the lack of a movement protein, it is possible that GEV-1 needs co-infection with another virus for its cell-to-cell movement and graft-transmissibility. Phylogenetic analyses revealed that GEV-1 is more closely related to the genus Enamovirus.
Based on these data, GEV-1 should be classified as a new member of the genus Enamovirus. Due to its sensitivity, HTS have been proposed as a diagnostic tool for biosecurity and quarantine surveillance [24-26]. Despite being a valuable tool for discovering novel viruses in metagenomic samples, information regarding the biological significance of a newly discovered virus such as pathogenicity, transmission, host range, and epidemiology often cannot be obtained by these means [27]. In addition, grapevines often present complex pathosystems, and further studies are needed to understand the interaction between these pathogens and their effect on the vines health, development, and quality of the grapes.

Acknowledgements This study was funded by Embrapa (Empresa Brasileira de Pesquisa Agropecuária, Brazil), Project 02.13.14.002. Scholarship of JMFS was supported by CNPq (Conselho Nacional de Desenvolvimento Científico e Tecnológico, Brazil). We thank Osmar Nickel for his kind review of the manuscript.

Author's contributions TVMF designed and supervised the study, and performed initial confirmation of infection and graft-transmissibility assays. MAR performed de novo assemblies and BLASTX searches, as well as primer design. Further bioinformatics analysis and $5^{\prime}$ RACE were performed by JMFS and RB. TN supervised the study. JMFS wrote the manuscript, and all authors contributed to the review.

\section{Compliance with ethical standards}

Conflict of interest The authors declare that they have no conflict of interest.

Ethical approval This article does not contain any studies with human participants or animals performed by any of the authors.

\section{References}

1. T.V.M. Fajardo, F.N. Silva, M. Eiras, O. Nickel, Trop. Plant. Pathol. (2017). doi:10.1007/s40858-017-0142-8

2. T.V.M. Fajardo, M. Eiras, O. Nickel, Trop. Plant. Pathol. 41, 246-253 (2016)

3. L.L. Domier, in Virus taxonomy. Ninth report of the International Committee on Taxonomy of Viruses, ed. by A.M.Q. King, M.J. Adams, E.B Carstens, E.J. Lefkowitz (Elsevier Academic, San Diego, 2012), pp. 1045-1053

4. K.A. Peter, F. Gildow, P. Palukaitis, S.M. Gray, J. Virol. 83(11), 5419-5429 (2009)

5. A. Ashoub, W. Rohde, D. Prüfer, Nucleic Acids Res. 26(2), 420-426 (1998)

6. E. Smirnova, A.E. Firth, W.A. Miller, D. Scheidecker, V. Brault, C. Reinbold, A.M. Rakotondrafara, B.Y. Chung, V. ZieglerGraff, PLoS Pathog. 11(5), e1004868 (2015)

7. H.M. Jaag, L. Kawchuk, W. Rohde, R. Fischer, N. Emans, D. Prüfer, Proc. Natl. Acad. Sci. U S A. 100(15), 8939-8944 (2003)

8. A.F. Fusaro, R.L. Correa, K. Nakasugi, C. Jackson, L. Kawchuk, M.F. Vaslin, P.M. Waterhouse, Virology 426(2), 178-187 (2012)

9. M. Pazhouhandeh, M. Dieterle, K. Marrocco, E. Lechner, B. Berry, V. Brault, O. Hemmer, T. Kretsch, K.E. Richards, P. Genschik, V. Ziegler-Graff, Proc. Natl. Acad. Sci. U S A 103(6), 1994-1999 (2006) 
10. X. Li, M.D. Ryan, J.W. Lamb, J. Gen. Virol. 81, 1857-1864 (2000)

11. A.E. Gorbalenya, E.V. Koonin, Soc. Sci. Rev. D. Physicochem. Biol. 11, 1-84 (1993)

12. C.E. Wobus, J.S. Skaf, M.H. Schultz, G.A. de Zoeten, J. Gen. Virol. 79, 2015-2023 (1999)

13. K. Mäkinen, T. Tamm, V. Naess, E. Truve, U. Puurand, T. Munthe, M. Saarma, J. Gen. Virol. 76, 2817-2825 (1995)

14. E.V. Koonin, V.V. Dolja, Crit. Rev. Biochem. Mol. Biol. 28(5), 375-430 (1993)

15. S. Liu, S. Sivakumar, Z. Wang, B.C. Bonning, W.A. Miller, Arch. Virol. 154(3), 469-479 (2009)

16. L.R. Newburn, K.A. White, Virology 479-480, 434-443 (2015)

17. M. Kozak, Nucleic Acids Res. 15(20), 8125-8148 (1987)

18. A.E. Firth, I. Brierley, J. Gen. Virol. 93, 1385-1409 (2012)

19. D.P. Giedroc, P.V. Cornish, Virus Res. 139(2), 193-208 (2009)

20. R. Lorenz, S.H. Bernhart, C. Höner Zu Siederdissen, H. Tafer, C. Flamm, P.F. Stadler, I.L. Hofacker, Algorithms Mol. Biol. 6, 26 (2011)
21. C.M. Brown, S.P. Dinesh-Kumar, W.A. Miller, J. Virol. 70(9), 5884-5894 (1996)

22. F. Moonan, J. Molina, T.E. Mirkov, Virology 269, 156-171 (2000)

23. I. Pagán, E.C. Holmes, J. Virol. 84(12), 6177-6187 (2010)

24. S. Massart, A. Olmos, H. Jijakli, T. Candresse, Virus Res. 188 , 90-96 (2014)

25. S. Bag, M. Al Rwahnih, A. Li, A. Gonzalez, A. Rowhani, J.K. Uyemoto, M.R. Sudarshana, Phytopathology 105(6), 840-846 (2015)

26. M. Al Rwahnih, S. Daubert, D. Golino, C. Islas, A. Rowhani, Phytopathology 105(6), 758-763 (2015)

27. S. Massart, T. Candresse, J. Gil, C. Lacomme, L. Predajna, M. Ravnikar, J.S. Reynard, A. Rumbou, P. Saldarelli, D. Škorić, E.J. Vainio, J.P. Valkonen, H. Vanderschuren, C. Varveri, T. Wetzel, Front. Microbiol. 8, 45 (2017)

28. S. Kumar, G. Stecher, K. Tamura, Mol. Biol. Evol. 33(7), 1870-1874 (2016) 